\title{
Bioactive Potential of Actinomycetes from Less Explored Ecosystems against Mycobacterium tuberculosis and Other Nonmycobacterial Pathogens
}

\author{
Radhakrishnan Manikkam, ${ }^{1}$ Gopikrishnan Venugopal, ${ }^{2}$ Balaji Subramaniam, ${ }^{3}$ \\ Balagurunathan Ramasamy, ${ }^{2}$ and Vanaja Kumar ${ }^{1}$ \\ ${ }^{1}$ Centre for Drug Discovery and Development, Sathyabama University, Chennai, Tamil Nadu 600 119, India \\ ${ }^{2}$ Department of Microbiology, Periyar University, Salem, Tamil Nadu 636 011, India \\ ${ }^{3}$ Department of Bacteriology, National Institute for Research in Tuberculosis, Chennai, Tamil Nadu 600 031, India \\ Correspondence should be addressed to Vanaja Kumar; vanaja_kumar51@yahoo.co.in
}

Received 23 May 2014; Accepted 20 October 2014; Published 9 November 2014

Academic Editor: Michael J. Palladino

Copyright (C) 2014 Radhakrishnan Manikkam et al. This is an open access article distributed under the Creative Commons Attribution License, which permits unrestricted use, distribution, and reproduction in any medium, provided the original work is properly cited.

\begin{abstract}
Bioactive potential of actinomycetes isolated from certain less explored Indian ecosystems against Mycobacterium tuberculosis and other nonmycobacterial pathogens was investigated. Actinomycetes were isolated from the soil samples collected from desert, coffee plantation, rubber forest, and hill area and their cultural and micromorphological characteristics were studied. Crude extracts were prepared by agar surface fermentation and tested against $M$. tuberculosis isolates by luciferase reporter phage (LRP) assay at $100 \mu \mathrm{g} / \mathrm{mL}$. Activity against nonmycobacterial pathogens was studied by agar plug method. Totally 54 purified cultures of actinomycetes including 43 Streptomyces and 11 non-Streptomyces were isolated. While screening for antitubercular activity, extracts of 39 actinomycetes showed activity against one or more $M$. tuberculosis isolates whereas 27 isolates exhibited antagonistic activity against nonmycobacterial pathogens. In particular crude extracts from sixteen actinomycete isolates inhibited all the three $M$. tuberculosis isolates tested. Findings of the present study concluded that less explored ecosystems investigated in this study are the potential resource for bioactive actinomycetes. Further purification and characterization of active molecule from the potential extracts will pave the way for determination of MIC, toxicity, and specificity studies.
\end{abstract}

\section{Introduction}

Tuberculosis (TB) caused by Mycobacterium tuberculosis is a highly prevalent infectious disease with almost one-third of global population believed to be infected [1]. According to statistics, India is the 17 th among the 22 high burden countries in terms of TB incidence rates [2]. Emergence of drug resistance among $M$. tuberculosis isolates and long term therapy using combination of drugs for its treatment are the major problem in TB control. Hence, there is an urgent need for new antitubercular drugs to fight against drug resistant $M$. tuberculosis strains [3]. The new anti-TB drugs are expected to have less side effects and improved pharmacokinetic properties with extensive and potent activity against drug resistant strains and/or should be able to reduce the total duration of treatment [4]. Secondary metabolites from microbial sources have a long history in the treatment of TB [5]. Actinomycetes are aerobic filamentous Gram-positive bacteria with true aerial hyphae, belonging to the phylum Actinobacteria (order Actinomycetales) [6]. Actinomycetes are common soil inhabitants with an unprecedented ability to produce clinically useful secondary metabolites including antibiotics. Of the total microbial bioactive metabolites, around 50\% are reported from the members of actinomycetes [7]. From the discovery of streptomycin, first antibiotic used for anti-TB therapy from Streptomyces griseus, numerous anti-TB antibiotics such as kanamycin and rifampicin have been reported from actinomycetes of terrestrial origin. In recent years, exploration of actinomycetes from routine ecosystems frequently results in reisolation of known actinomycetes and antibiotics. Instead, 
bioprospecting of un/less explored ecosystems like marine, desert, forests, caves, and hills has been proved as useful method for tapping innumerable number of bioactive compounds from novel bioactive actinomycetes [7-10] including anti-TB metabolites [11]. Bioprospecting of actinomycetes from certain less explored ecosystems in India with special reference to antitubercular activity was attempted in the present work. Antagonistic activity of actinomycetes against nonmycobacterial pathogens was also studied.

\section{Materials and Methods}

2.1. Description and Characterization of Actinomycetes. Actinomycetes were isolated from soil samples collected from the rare ecosystems, namely, (i) Thar desert, Rajasthan; (ii) Rubber forest, Kerala; (iii) Coffee plantation, Kerala; (iv) Western Mountain, Thirukurungudi, Tamil Nadu; (v) Thotabeta hills, Tamil Nadu; (vi) Siruvani hill area, Tamil Nadu; (vii) Yercaud hills, Tamil Nadu; and (viii) Munnar hill area, Tamil Nadu. The collected samples were dried at $28^{\circ} \mathrm{C}$ for $2 \mathrm{~d}$. Actinomycetes were isolated by adopting standard spread plate method using starch casein nitrate agar medium [12] supplemented with nalidixic acid and nystatin to retard the growth of bacteria and fungi, respectively. Growth of actinomycetes was maintained on yeast extract malt extract (YEME) agar (ISP medium 2) [13] as well as in 30\% glycerol broth.

Cultural characterization was done by inoculating all the actinomycete cultures into YEME agar medium [13]. Micromorphological characteristics were studied by adopting slide culture method [14]. Based on growth pattern of actinomycetes on YEME agar medium and microscopic appearance, similar actinomycete isolates were discarded and the ones that were exhibiting different characteristics were selected for further investigations.

2.2. Small Scale Production of Bioactive Metabolites. Bioactive metabolites from actinomycetes were produced by agar surface fermentation. All the actinomycete cultures were inoculated into two YEME agar plates each and incubated at $28^{\circ} \mathrm{C}$ for $10 \mathrm{~d}$. After scraping out the mycelial growth, the agar medium was cut into pieces and metabolites secreted extracellularly into the agar medium were extracted using $50 \mathrm{~mL}$ of methanol for $24 \mathrm{~h}$. The methanol portion was collected and concentrated using eppendorf concentrator at $30^{\circ} \mathrm{C}$ and quantified [15]. One mg per $\mathrm{mL}$ of working concentration of crude extract was prepared using 10\% dimethyl sulfoxide (DMSO) prepared in sterile distilled water and filtered using $0.45 \mu$ filters.

2.3. In Vitro Screening for Antitubercular Activity. Antitubercular activity of actinomycete extracts was studied against standard laboratory strain Mycobacterium tuberculosis $\mathrm{H} 37 \mathrm{Rv}$, SHRE (streptomycin, isoniazid, rifampicin, and ethambutol) sensitive, and SHRE resistant clinical isolates of $M$. tuberculosis by adopting LRP assay [16]. All the $M$. tuberculosis isolates were obtained from the Department of Bacteriology, National Institute for Research in Tuberculosis.
Viability of all the isolates was maintained on LJ slopes. High titre of mycobacteriophage phAE129 used in this study was prepared using M. smegmatis $\mathrm{mc}^{2} 155$ in Middlebrook $7 \mathrm{H} 9$ complete medium [17].

About $350 \mu \mathrm{L}$ of G7H9 broth supplemented with $10 \%$ albumin dextrose complex and $0.5 \%$ glycerol was taken in cryovials and added with $50 \mu \mathrm{L}$ of crude extract in order to get the final concentration of $100 \mu \mathrm{g} / \mathrm{mL}$. $100 \mu \mathrm{L}$ of $M$. tuberculosis cell suspension was added to all the vials. The above procedure was followed for all the three $M$. tuberculosis isolates. DMSO (1\%) was also included in the assay as solvent control. All the vials were incubated at $37^{\circ} \mathrm{C}$ for $72 \mathrm{~h}$. After incubation, $50 \mu \mathrm{L}$ of high titre phage phAE129 and $40 \mu \mathrm{L}$ of $0.1 \mathrm{M} \mathrm{CaCl}_{2}$ solution were added to the test and control vials. All the vials were incubated at $37^{\circ} \mathrm{C}$ for $4 \mathrm{~h}$. After incubation, $100 \mu \mathrm{L}$ from each vial was transferred to luminometer cuvette. About $100 \mu \mathrm{L}$ of D-Luciferin was added and relative light unit (RLU) was measured in luminometer (Monolight 2010):

$$
\begin{aligned}
& \text { Percentage RLU reduction } \\
& \qquad=\frac{\text { Control RLU }- \text { Test RLU }}{\text { Control RLU }} \times 100 .
\end{aligned}
$$

Extracts showing RLU reduction by $50 \%$ or more when compared to control were considered as having antitubercular activity. Actinomycetes which showed activity against all the three $M$. tuberculosis isolates were selected and tested in triplicate against the same $M$. tuberculosis isolates and nonmycobacterial pathogens. The mean values of the results were calculated.

2.4. In Vitro Screening against Nonmycobacterial Pathogens. Test pathogens used in this study include standard strains Staphylococcus aureus MTCC96, Bacillus subtilis MTCC441, clinical isolates of Escherichia coli, Salmonella typhi, Klebsiella pneumoniae, Proteus vulgaris, Pseudomonas aeruginosa, and Candida albicans. All the nonmycobacterial pathogens were obtained from the Department of Microbiology, Periyar University, Tamil Nadu. Test pathogens were inoculated onto Muller Hinton Agar (MHA) plates using sterile cotton swab. Actinomycete cultures were inoculated onto YEME agar plates $(20 \mathrm{~mL} /$ plate $)$ and incubated at $28^{\circ} \mathrm{C}$ for $10 \mathrm{~d}$. After scraping the mycelial growth, $5 \mathrm{~mm}$ diameter agar plugs were taken and placed over MHA plates seeded with test pathogens. All the plates were incubated at $37^{\circ} \mathrm{C}$ for $24 \mathrm{~h}$ for bacteria and $48 \mathrm{~h}$ for fungi. Agar plug prepared from uninoculated YEME agar was included as medium control. Zone of inhibition was expressed in millimetre in diameter [15].

\section{Results}

3.1. Isolation and Characterization of Actinomycetes. Seventytwo actinomycete isolates were isolated from soil samples collected from different ecosystems. Based on the microscopic and cultural characteristics, 54 different actinomycete isolates were selected after dereplication of 18 isolates. Fifty out of 54 isolates produced good growth with powdery consistency on 
TABLE 1: Growth and morphological pattern of actinomycetes isolated from different rare ecosystems.

\begin{tabular}{|c|c|c|}
\hline Characteristics & Appearance & $\begin{array}{l}\text { Number of } \\
\text { isolates (\%) }\end{array}$ \\
\hline \multirow{2}{*}{ Growth } & Good & $50(92 \%)$ \\
\hline & Moderate & $4(7 \%)$ \\
\hline \multirow{2}{*}{ Consistency } & Powdery & $45(83 \%)$ \\
\hline & Leathery & $9(16 \%)$ \\
\hline \multirow{6}{*}{ Aerial mass colour } & White & $26(48 \%)$ \\
\hline & Gray & $20(37 \%)$ \\
\hline & Green & $2(3 \%)$ \\
\hline & Blue & $1(2 \%)$ \\
\hline & Orange & $2(3.70 \%)$ \\
\hline & Pink & $3(5.55 \%)$ \\
\hline Reverse side pigment & & $17(31.48 \%)$ \\
\hline Soluble pigment & & $18(33.33 \%)$ \\
\hline \multirow{2}{*}{ Micromorphology } & $\begin{array}{l}\text { Aerial and substrate } \\
\text { mycelium }\end{array}$ & $53(98.14 \%)$ \\
\hline & $\begin{array}{l}\text { Substrate mycelium } \\
\text { alone }\end{array}$ & $1(1.85 \%)$ \\
\hline \multirow{4}{*}{$\begin{array}{l}\text { Spore chain } \\
\text { morphology }\end{array}$} & Rectus flexible (RF) & $34(62.96 \%)$ \\
\hline & $\begin{array}{l}\text { Retinaculum apertum } \\
\text { (RA) }\end{array}$ & $6(11.11 \%)$ \\
\hline & Spirals (S) & $2(3.70 \%)$ \\
\hline & Others & $12(22.22 \%)$ \\
\hline
\end{tabular}

YEME agar. Majority of the isolates produced either white $(48 \%)$ or gray $(37 \%)$ colour aerial mycelium. Reverse side colour and colour of soluble pigments produced by these actinomycetes include brown, yellow, pink, green, blue, and orange. In micromorphological study, except the strain S28, all the actinomycete isolates showed the presence of substrate and aerial mycelium with different length and arrangement. In 34 (62.96\%) isolates, the aerial mycelium was of rectiflexibile (RF) type (Table 1). Based on the observed phenotypic characteristics, 43 actinomycete isolates $(79.62 \%)$ were tentatively identified as Streptomyces sp. and 11 (20.37\%) isolates were identified as nonstreptomyces/rare actinomycetes.

3.2. Production and Antitubercular Activity of Actinomycete Extracts. All the actinomycete isolates showed growth on YEME agar medium. Overall about $30-40 \mathrm{mg}$ of crude extract was obtained from $50 \mathrm{~mL}$ of YEME agar medium inoculated with actinomycetes. Extracts from 39 (72.22\%) out of 54 isolates inhibited one or more of $M$. tuberculosis isolates tested. Extracts of 16 (29.62\%) actinomycete isolates inhibited the growth of all the three strains, namely, standard strain M. tuberculosis H37Rv, SHRE sensitive, and SHRE resistant M. tuberculosis isolates. Extracts of 24 (44.44\%) actinomycetes inhibited the standard strain $M$. tuberculosis H37Rv, whereas the SHRE sensitive and SHRE resistant $M$. tuberculosis isolates were inhibited by the extracts of 23 (42.59\%) actinomycetes (Table 2).
The diversity of antagonistic activity exhibited by the actinomycetes is given in Table 3 . In total, 43 (79.63\%) actinomycetes showed antagonistic activity against one or more of the 11 pathogens tested. Eleven (20.37\%) actinomycetes failed to inhibit any of the test pathogens. Another eleven isolates (20.37\%) were active against one or more number of M. tuberculosis isolates, Gram positive bacteria, and Gram negative bacteria. Eight (14.81\%) isolates were active only against Gram positive bacteria and $M$. tuberculosis isolates whereas one each exclusively inhibited Gram positive bacteria (Y1), Gram negative bacteria (M17), fungi (CSA19), Gram positive and Gram negative bacteria (Y32), and M. tuberculosis and Gram negative bacteria (M7). Only two isolates, K8 and TA36, inhibited both M. tuberculosis isolates and C. albicans without showing activity against any other bacterial pathogens. The only strain CSA15, isolated from coffee plantation soil, showed activity against all the M. tuberculosis isolates, Gram positive and Gram negative bacteria and fungi. Thus, diverse antagonistic activity was exhibited by the actinomycetes isolated from all the rare ecosystems investigated in this study.

3.3. Antagonistic Activity against Nonmycobacterial Pathogens. In agar plug method, 27 isolates, that is, $50 \%$ of the actinomycete isolates, showed inhibition against at least one or more number of nonmycobacterial pathogens tested. Maximum of 17 (31.48\%) and 16 (29.62\%) isolates were active against S. aureus MTCC96 and B. subtilis MTCC441, respectively. Among the Gram negative bacteria, $P$. vulgaris was inhibited by $11(20.37 \%)$ actinomycetes. None of the isolates were found to be active against $P$. aeruginosa. Four (5.55\%) actinomycetes inhibited the growth of C. albicans (Table 2). Ten out of 18 soluble pigment producers were found to exhibit antibacterial activity. The crude ethyl acetate extracts from 16 selected actinomycete isolates showed activity against the bacterial pathogens and $M$. tuberculosis strains tested. The mean value of activity is presented in Table 4 .

\section{Discussion}

Pathogenic microorganisms have evolved sophisticated mechanisms to inactivate antibiotics and rendered an urgent need for new antibiotics that would target the emerging multidrug resistance [18]. Consequently, search for novel sources of potent antibiotics is desperately needed to develop potent drugs. Microbial resources have made an incredible contribution to the antibiotic drug discovery and development process over the last seven decades [19]. In particular, actinomycetes are the most important source of bioactive natural compounds with a long track record of producing novel molecules [20]. The present study reported the bioactive potential of actinomycetes isolated from less explored ecosystems against $M$. tuberculosis and other nonmycobacterial pathogens.

According to Bérdy [7] great number of antibiotic compounds exhibit exclusive activities against Gram positive bacteria while only $1.5 \%$ are active against Gram negative bacteria. In the present study, $50 \%$ of the actinomycetes 


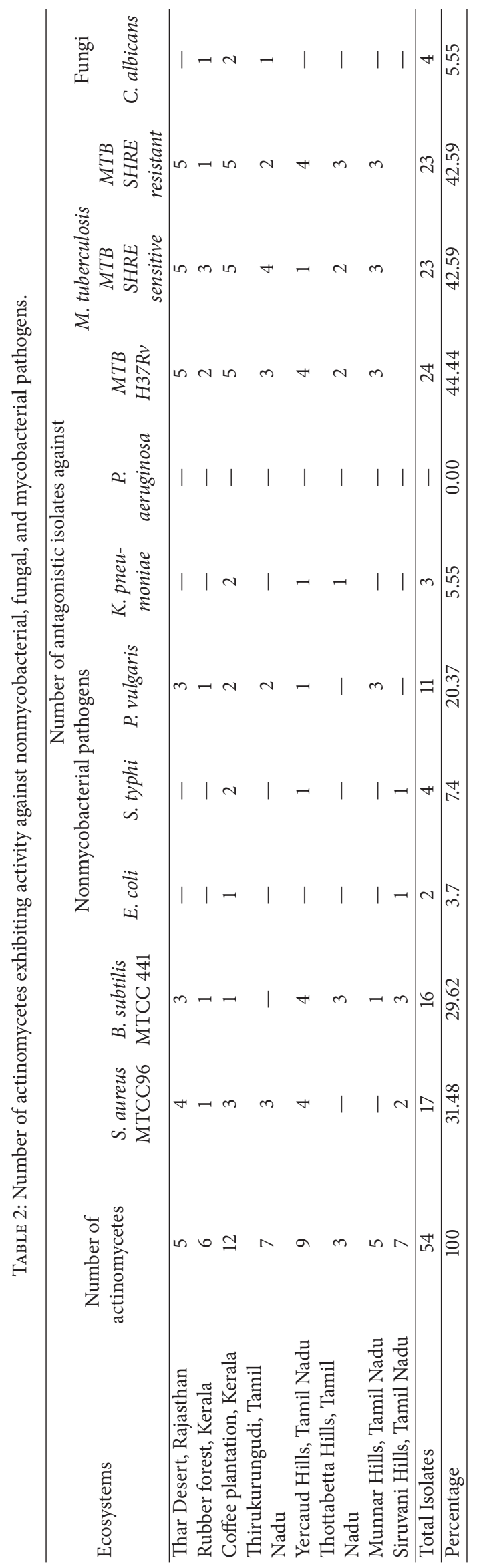


International Scholarly Research Notices

5

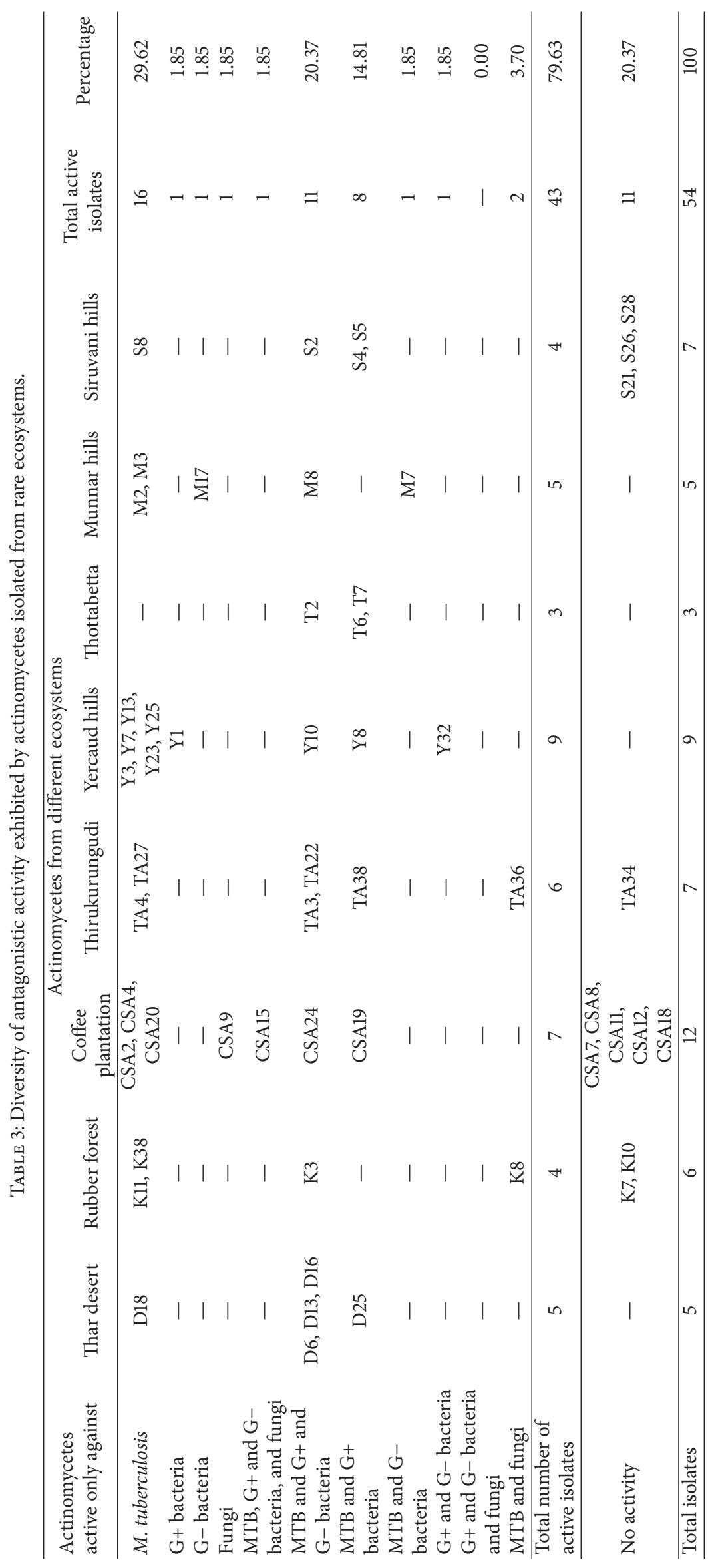




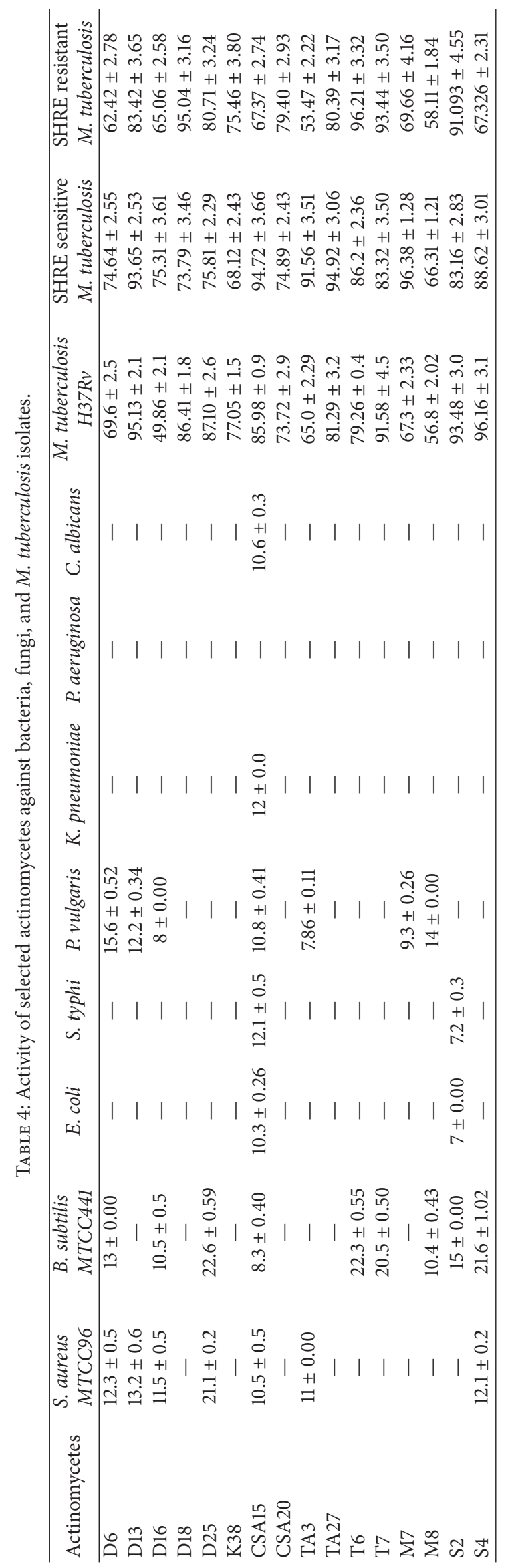


isolated from rare ecosystems showed activity against nonmycobacterial pathogens, whereas $72 \%$ of the isolates are found to inhibit sensitive and/or resistant strains of $M$. tuberculosis. Similar to earlier reports [21, 22] more number of actinomycetes showed inhibited Gram positive bacteria compared to Gram negative bacteria.

Wide variation in the percentage of active isolates and in their activity spectra has been reported from different ecosystems $[6,22,23]$. Eleven different patterns of activities were recorded against 11 test organisms. The key observations made in this analysis include the following: (i) antagonistic isolates are distributed in all the ecosystems studied; (ii) the maximum number of isolates $(29.62 \%)$ is exclusively active against M. tuberculosis followed by $20.37 \%$ of the isolates inhibiting Gram positive and Gram negative bacteria and M. tuberculosis. The broad spectrum of activity detected in some of the Streptomyces isolates in this study could be due to different antimicrobial compounds produced by the isolates, each one with a species- or group-specific activity [22] and/or to the presence of more than one compound with broad spectrum of action like the antibiotic meroparamycin which is active against Gram positive bacteria, yeasts, and filamentous fungi [24], among others. These findings clearly evidenced that antagonistic actinomycetes isolated from rare ecosystems are potential sources for compounds showing antibacterial and antituberculous activity.

Certain issues are associated with primary screening in solid medium and liquid culture based secondary screening. There can be loss of bioactive metabolite production in secondary screening while using a medium which is different from the one used for primary screening. Certain actinomycete strains produce antibiotic compounds only in solid medium but fail to produce the same in liquid medium [2527]. Moreover, the whole organism based primary screening methods like cross streak/cross spot methods are not suitable for highly biohazardous organisms like M. tuberculosis. To address all these issues, agar plugs which contain the extracellular bioactive compounds were tested against nonmycobacterial pathogens. The crude extract from the same medium was tested against $M$. tuberculosis. Most of the secondary metabolites including antibiotics are extracellular in nature and extracellular products of actinomycetes exhibit potent antimicrobial activities [28-31]. Similar observations were made in the present study.

There are number of mycobacterial drug susceptibility assays used for the screening of natural products described over the period of time [32]. Screening methods using LJ or 7H11 agar require large amounts of crude extracts or purified compounds to be incorporated in the media. It also requires about three or more weeks of incubation to produce results. Conventional testing using LJ slants is unsuitable for screening uncharacterised novel compounds whose heat stability is unknown. LRP assay used in this study is a rapid, liquid culture based and less laborious method for high throughput screening of a large number of compounds for antimycobacterial activity [33]. As a broth based method, LRP assay qualifies to be ideal for screening such novel compounds. The need for only small quantity of the extracts/compounds to obtain results within 3 days qualifies the test further. Natural products from various natural sources like plants, actinomycetes, and fungi $[16,34$, 35] and synthetic compounds [36] had been screened for antitubercular activity by adopting LRP assay.

Antibiotics isolated and characterised from strains that show broad spectrum activity can be used to treat varied microbial infections. The availability of such drugs across the counter and wide usage of the same may lead to the emergence and spread of drug resistance among the existing pathogens [37]. Selection of antibiotics that are exclusively acting against $M$. tuberculosis and/or limited number of nonmycobacterial pathogens may circumvent this problem.

\section{Conclusion}

Findings of the present work concluded that less explored ecosystems investigated in this study are the potential resource for bioactive actinomycetes. However, in this study, only the crude extracts were evaluated and found to be active against Mycobacterium tuberculosis and other nonmycobacterial pathogens. In general, crude extracts are complex mixture of compounds. So additional research like bioassay guided fractionation and characterization will be needed to validate whether a single useful compound can be found and it is also needed to determine the MIC and meaningful toxicity and specificity studies. In particular, isolation and characterization of active molecule from the potential strains like D25, CSA15 will pave the way for the development of promising antibiotics against $M$. tuberculosis and other nonmycobacterial pathogens.

\section{Conflict of Interests}

The authors declare that there is no conflict of interests regarding the publication of this paper.

\section{References}

[1] B. Mukhopadhyay and N. K. Ganguly, "Tuberculosis research in India," Current Science, vol. 105, no. 5, pp. 594-596, 2013.

[2] R. S. Kashyap, A. R. Nayak, A. A. Husain et al., "Tuberculosis in India: the continuing challenge," Current Science, vol. 105, no. 5, pp. 597-606, 2013.

[3] A. M. Ginsberg, "Drugs in development for tuberculosis," Drugs, vol. 70, no. 17, pp. 2201-2214, 2010.

[4] M. V. N. de Souza, "Promising drugs against tuberculosis," Recent Patents on Anti-Infective Drug Discovery, vol. 1, no. 1, pp. 33-44, 2006.

[5] E. J. Ashforth, C. Fu, X. Liu et al., "Bioprospecting for antituberculosis leads from microbial metabolites," Natural Product Reports, vol. 27, no. 11, pp. 1709-1719, 2010.

[6] M. George, A. Anjumol, G. George, and A. A. M. Hatha, "Distribution and bioactive potential of soil actinomycetes from different ecological habitats," African Journal of Microbiological Research, vol. 6, no. 10, pp. 2265-2271, 2012.

[7] J. Bérdy, "Thoughts and facts about antibiotics: where we are now and where we are heading," Journal of Antibiotics, vol. 65, no. 8, pp. 385-395, 2012. 
[8] L. A. Maldonado, W. Fenical, P. R. Jensen et al., "Salinispora arenicola gen. nov., sp. nov. and Salinispora tropica sp. nov., obligate marine actinomycetes belonging to the family Micromonosporaceae," International Journal of Systematic and Evolutionary Microbiology, vol. 55, no. 5, pp. 1759-1766, 2005.

[9] W. N. Hozzein and M. Goodfellow, "Streptomyces synnematoformans sp. nov., a novel actinomycete isolated from a sand dune soil in Egypt," International Journal of Systematic and Evolutionary Microbiology, vol. 57, no. 9, pp. 2009-2013, 2007.

[10] J. Nachtigall, A. Kulik, S. Helaly et al., "Atacamycins A-C, 22membered antitumor macrolactones produced by Streptomyces sp. C38," Journal of Antibiotics, vol. 64, no. 12, pp. 775-780, 2011.

[11] Q. Wang, F. Song, X. Xiao et al., "Abyssomicins from the South China Sea deep-sea sediment verrucosispora sp.: natural thioether michael addition adducts as antitubercular prodrugs," Angewandte Chemie-International Edition, vol. 52, no. 4, pp. 1231-1234, 2013.

[12] D. P. Labeda and M. C. Shearer, "Isolation of actinomycetes for biotechnological applications," in Isolation of Biotechnological Organisms from Nature, D. P. Labeda, Ed., vol. 19, pp. 1-19, McGraw-Hill, New York, NY, USA, 1990.

[13] E. B. Shirling and D. Gottileb, "Methods for characterization of Streptomyces species," International Journal of Systematic Bacteriology, vol. 16, no. 3, pp. 313-340, 1966.

[14] R. Balagurunathan, M. Radhakrishnan, and S. T. Somasundaram, "L-glutaminase producing actinomycetes from marine sediments-selective isolation, semi quantitative assay and characterization of potential strain," Australian Journal of Basic and Applied Sciences, vol. 4, no. 5, pp. 698-705, 2010.

[15] G. P. Eccleston, P. R. Brooks, and D. I. Kurtböke, “The occurrence of bioactive micromonosporae in aquatic habitats of the Sunshine Coast in Australia," Marine Drugs, vol. 6, no. 2, pp. 243-261, 2008.

[16] M. Radhakrishnan, S. Suganya, R. Balagurunathan, and V. Kumar, "Preliminary screening for antibacterial and antimycobacterial activity of actinomycetes from less explored ecosystems," World Journal of Microbiology and Biotechnology, vol. 26, no. 3, pp. 561-566, 2010.

[17] V. Kumar, S. Balaji, N. S. Gomathi et al., "Phage cocktail to control the exponential growth of normal flora in processed sputum specimens grown overnight in liquid medium for rapid TB diagnosis," Journal of Microbiological Methods, vol. 68, no. 3, pp. 536-542, 2007.

[18] M. S. Butler, M. A. Blaskovich, and M. A. Cooper, "Antibiotics in the clinical pipeline in 2013," Journal of Antibiotics, vol. 66, no. 10, pp. 571-591, 2013.

[19] A. L. Demain and S. Sanchez, "Microbial drug discovery: 80 years of progress," Journal of Antibiotics, vol. 62, no. 1, pp. 5-16, 2009.

[20] P. A. Jose and S. R. D. Jebakumar, "Unexplored hypersaline habitats are sources of novel actinomycetes," Frontiers in Microbiology, vol. 5, article 242, 3 pages, 2014.

[21] M. Radhakrishnan, S. Balaji, and R. Balagurunathan, "Thermotolerant actinomycetes from Himalayan mountain-antagonistic potential, characterization and identification of selected strains," Malaysian Applied Biology, vol. 36, pp. 59-65, 2007.

[22] S. P. Salamoni, M. B. Mann, F. S. Campos, A. C. Franco, J. C. Germani, and S. T. van der Sand, "Preliminary characterization of some Streptomyces species isolated from a composting process and their antimicrobial potential," World Journal of Microbiology and Biotechnology, vol. 26, no. 10, pp. 1847-1856, 2010.

[23] N. Sahin and A. Ugur, "Investigation of the antimicrobial activity of some Streptomycetes isolates," Turkish Journal of Biology, vol. 27, pp. 79-84, 2003.

[24] M. Y. El-Naggar, S. A. El-Assar, and S. M. Abdul-Gawad, "Meroparamycin production by newly isolated Streptomyces sp. strain MAR01: taxonomy, fermentation, purification and structural elucidation," Journal of Microbiology, vol. 44, no. 4, pp. 432-438, 2006.

[25] S. B. Ilic, S. S. Konstantinovic, Z. B. Todorovic et al., "Characterization and antimicrobial activity of the bioactive metabolites in streptomycete isolates," Microbiology, vol. 76, no. 4, pp. 421-428, 2007.

[26] M. Anibou, A. Chait, A. Zyad, M. Taourirt, Y. Ouhdouch, and A. Benherref, "Actinomycetes from Moroccan habitats: isolation and screening for cytotoxic activities," World Journal of Microbiology and Biotechnology, vol. 24, no. 10, pp. 2019-2025, 2008.

[27] S. Radhika, S. Bharathi, M. Radhakrishnan, and R. Balagurunathan, "Bioprospecting of fresh water actinobacteria: isolation, characterization and antagonistic potential of selected actinobacterial," Journal of Pharmacy Research, vol. 4, pp. 25842586, 2011.

[28] M. Radhakrishnan, D. Saravanan, R. Balagurunathan, and V. Kumar, "Fungal bioproespecting from sundarban mangrove forest with special reference to antibacterial and antimycobacterial activity," International Journal of PharmTech Research, vol. 3, no. 2, pp. 719-723, 2011.

[29] S. K. Augustine, S. P. Bhavsar, and B. P. Kapadnis, "A nonpolyene antifungal antibiotic from Streptomyces albidoflavus $\mathrm{PU}$ 23," Journal of Biosciences, vol. 30, no. 2, pp. 201-211, 2005.

[30] M. V. Arasu, V. Duraipandiyan, P. Agastian, and S. Ignacimuthu, "Antimicrobial activity of Streptomyces spp. ERI-26 recovered from Western Ghats of Tamil Nadu," Journal de Mycologie Medicale, vol. 18, no. 3, pp. 147-153, 2008.

[31] D. Mohanraj, S. Bharathi, M. Radhakrishnan, and R. Balagurunathan, "Bioprospecting of actinobacteria from Yelagiri hills with special reference to antibacterial activity," Journal of Chemical and Pharmaceutical Research, vol. 3, no. 3, pp. 439446, 2011.

[32] J. G. B. Sánchez and V. V. Kouznetsov, "Antimycobacterial susceptibility testing methods for natural products research," Brazilian Journal of Microbiology, vol. 41, no. 2, pp. 270-277, 2010.

[33] W. R. Jacobs Jr., R. G. Barletta, R. Udani et al., "Rapid assessment of drug susceptibilities of Mycobacterium tuberculosis by means of luciferase reporter phages," Science, vol. 260, no. 5109, pp. 819-822, 1993.

[34] S. Prabuseenivasan and V. Kumar, "Antimycobacterial activity of selected plant essential oils," in Proceedings of the National Seminar on Microbial Biotechnology, R. Balagurunathan and M. Radhakrishnan, Eds., p. 206, Tamil Nadu, India, 2006.

[35] A. Molly, J. James, C. S. Misra, L. D. M. Sahadevan, T. Arunkumar, and V. Thankamani, "Antimycobacterial activity of the plant extracts of Alstonia scholaris," International Journal of Current Pharmaceutical Research, vol. 4, pp. 40-42, 2012. 
[36] V. Raparti, T. Chitre, K. Bothara et al., "Novel 4-(morpholin4-yl)- $\mathrm{N}^{\prime}$-(arylidene)benzohydrazides: synthesis, antimycobacterial activity and QSAR investigations," European Journal of Medicinal Chemistry, vol. 44, no. 10, pp. 3954-3960, 2009.

[37] A. S. Coco, M. A. Horst, and A. S. Gambler, "Trends in broadspectrum antibiotic prescribing for children with acute otitis media in the United States, 1998-2004," BMC Pediatrics, vol. 9, article 41, 2009. 

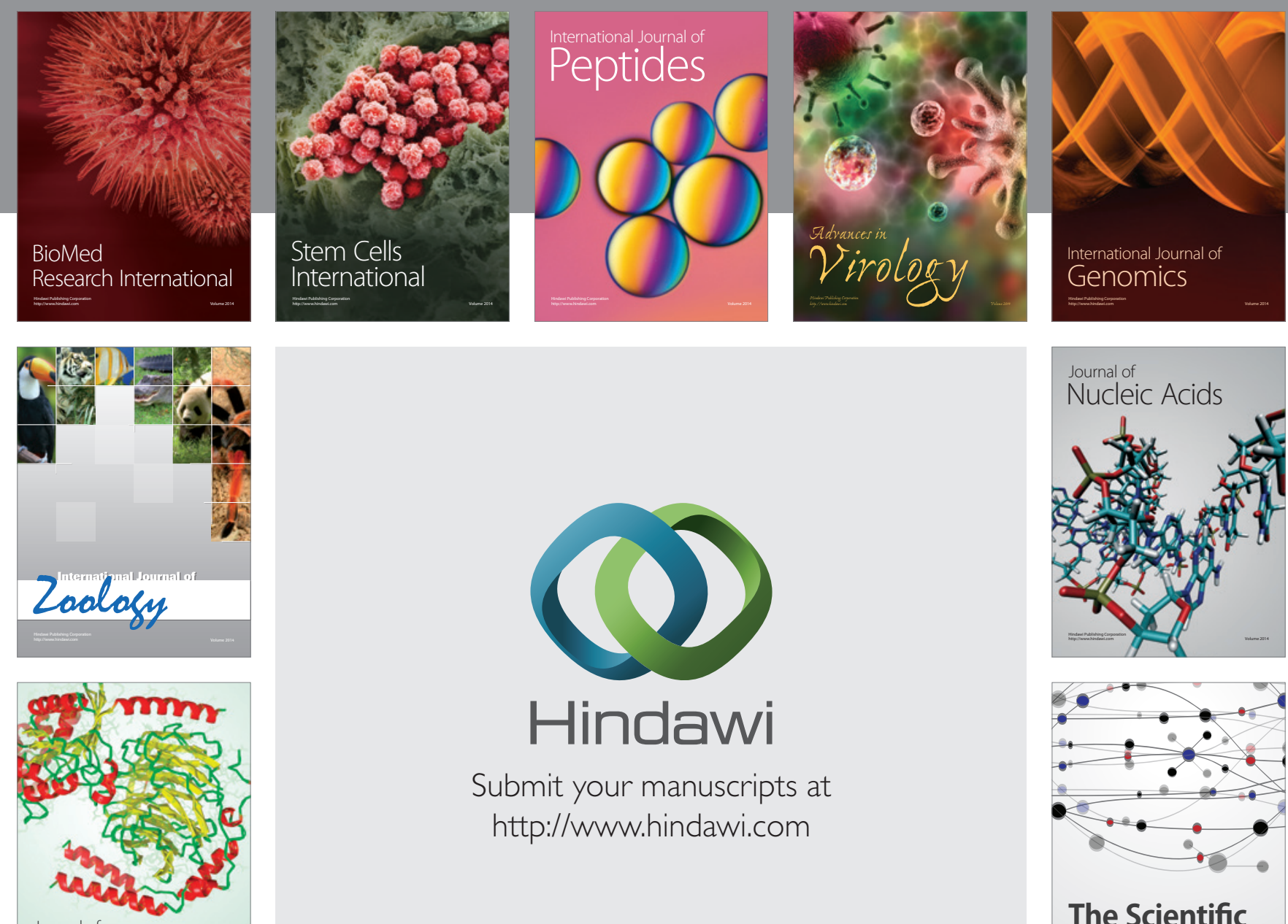

Submit your manuscripts at

http://www.hindawi.com

Journal of
Signal Transduction
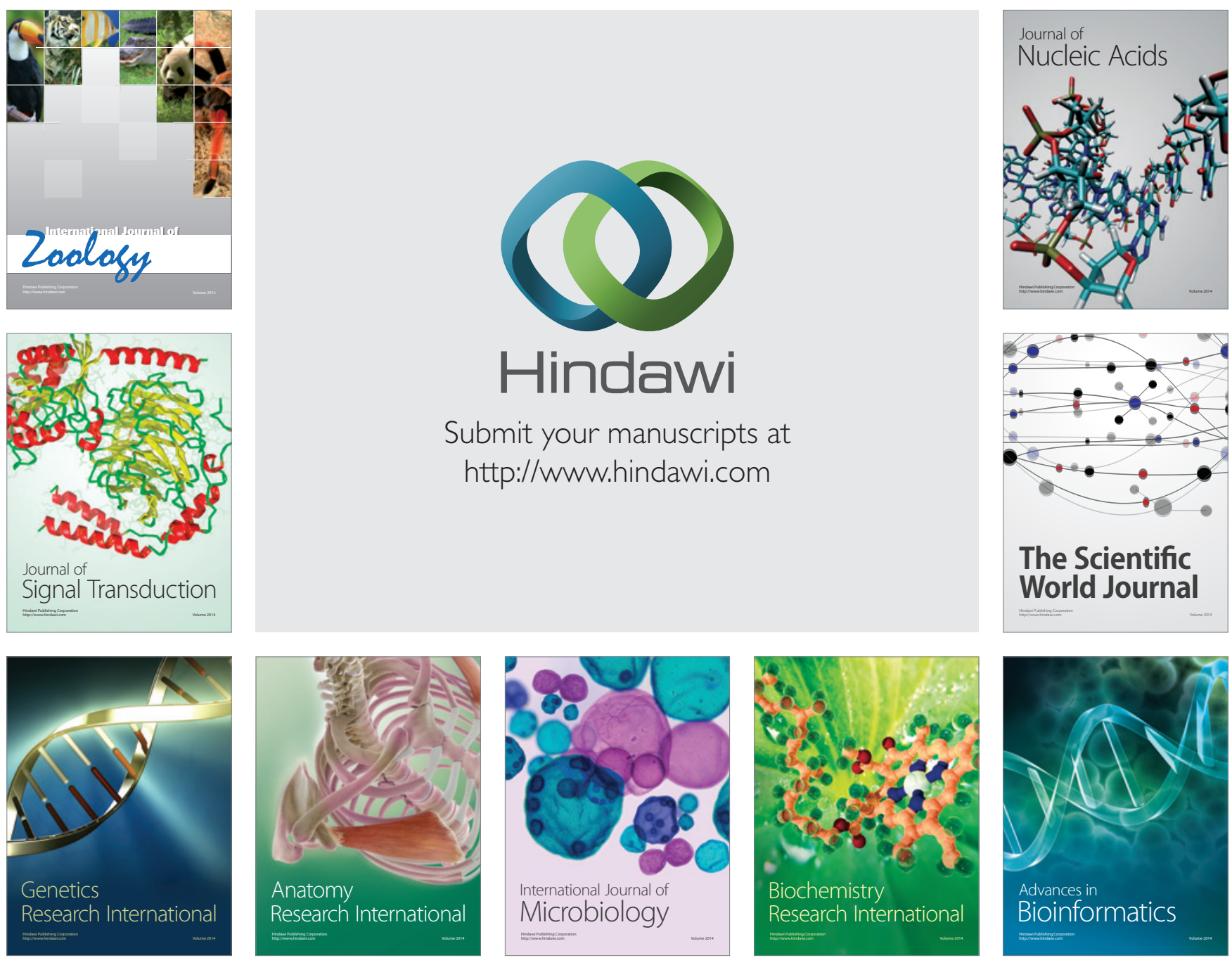

The Scientific World Journal
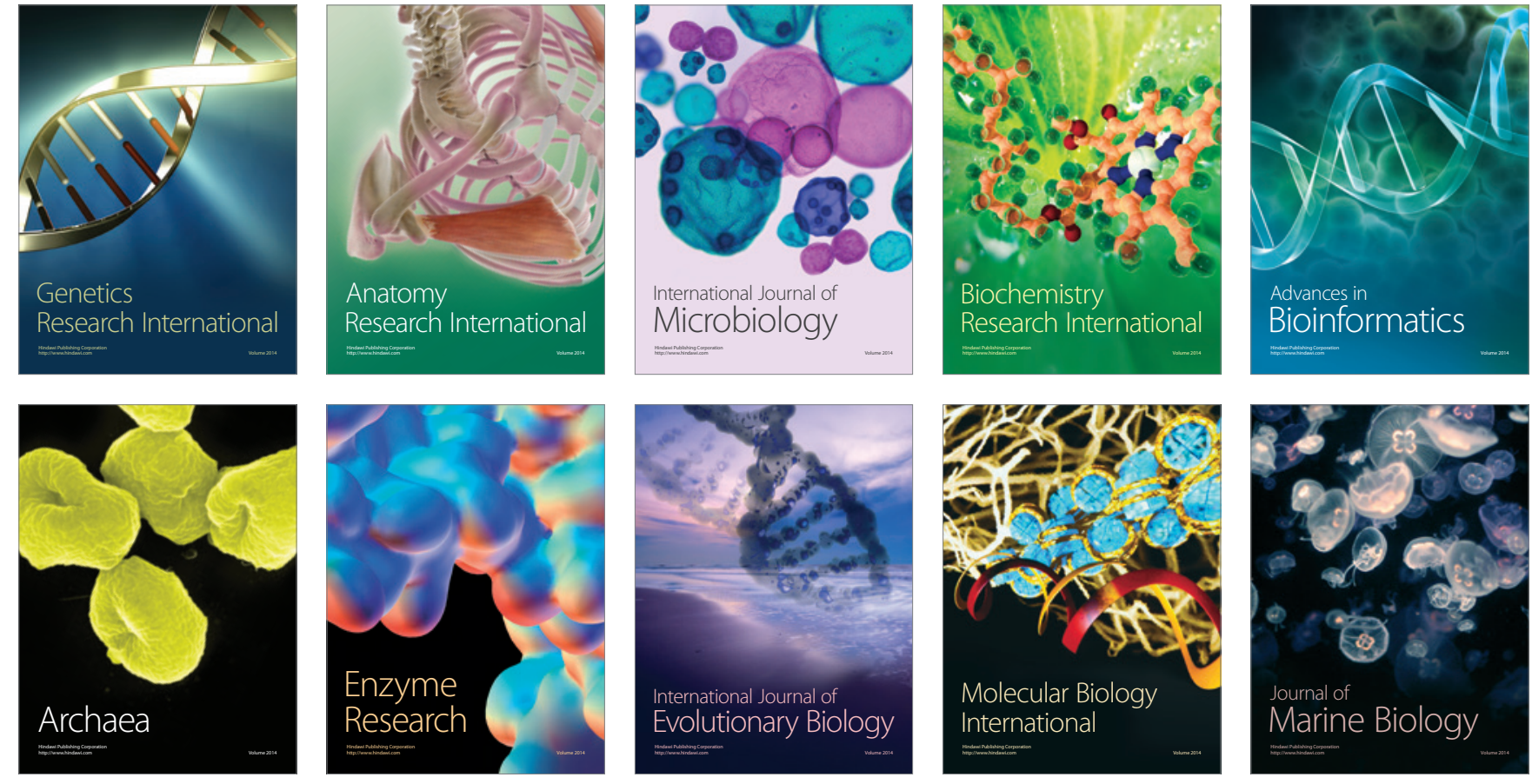